\title{
PELATIHAN INOVASI PEMBELAJARAN MENGAHADAPI MASA PANDEMIC COVID-19
}

\author{
Nanda Safarati ${ }^{1}$, Rahma $^{2}$, Fatimah $^{3}$, Sharfina $^{4}$ \\ ${ }^{1,2,3,4)}$ Program Studi Pendidikan Fisika, Fakultas Keguruan dan Ilmu Pendidikan, Universitas Almuslim \\ e-mail: nandasafarati@umuslim.ac.id
}

\begin{abstract}
Abstrak
Pengabdian kepada masyarakat program studi Pendidikan Fisika bertujuan memberikan solusi terhadap permasalahan tersebut dengan mengadakan pelatihan pengembangan inovasi pembelajaran dalam menghadapi masa pandemic covid-19. Melalui kegiatan ini, tim pengabdian kepada masyarakat Program Studi Pendidikan Fisika memberikan pelatihan dan pendampingan terhadap praktisi pendidikan dalam mengembangkan strategi pembelajaran yang dapat digunakan di era new normal. Kegiatan webinar nasional yang bertemakan "Pelatihan Inovasi Pembelajaran Mengahadapi Masa Pandemic Covid-19" tersebut dihadiri oleh praktisi pendidikan dari seluruh Indonesia termasuk dosen, guru, mahasiswa dan praktisi pendidikan lainnya. Peserta yang mengikuti kegiatan webinar nasional ini berjumlah 148 orang yang terdiri dari 46 dosen, 44 guru, 44 mahasiswa dan 14 orang lainnya. Kegiatan webinar ini berlangsung selama 4 hari yaitu pada tanggal 8, 9, 15 dan 16 Juli 2020. Berdasarkan tanggapan peserta yang mengikuti webinar ini didapatkan informasi bahwa para pendidik sangat antusias mengikuti kegiatan ini dikarenakan materi yang disampaikan dalam kegiatan tersebut masih baru bagi mereka.
\end{abstract}

Kata Kunci: Pelatihan, Inovasi Pembelajaran, Pandemic Covid-19

\begin{abstract}
Community service for the Physics Education study program aims to provide solutions to these problems by holding training on developing learning strategies in the new normal era. Through this activity, the community service team of the Physics Education Study Program provides training and mentoring for education practitioners in developing learning strategies that can be used in the new normal era. The national webinar activity with the theme "tips for developing learning strategies in the new normal era" was attended by education practitioners from all over Indonesia including lecturers, teachers, students and other education practitioners. Participants who took part in this national webinar were 148 people consisting of 46 lecturers, 44 teachers, 44 students and 14 other people. This webinar activity lasted for 4 days, namely on July 8, 9, 15 and 16, 2020. Based on the responses of the participants who took part in this webinar, information was obtained that educators were very enthusiastic about participating in this activity because the material presented in the activity was still new to them
\end{abstract}

Keywords: Training, Leaning Innovation, Covid-19 Pandemic

\section{PENDAHULUAN}

Dunia pendidikan di era pandemic sekarang ini mengalami perubahan yang sangat signifikan bagi seluruh praktisi pendidikan baik itu untuk dosen/ guru, anak didik dan orang tua. Seluruh kegiatan pembelajaran dialihkan memakai sistem online atau daring. Semua unsur yang terlibat didalam dunia pendidikan mengalami dampak dengan keadaan ini. Semua unsur terkait memikirkan bagaimana cara agar dunia pendidikan tidak berhenti sampai disini.

Tanggal 24 Maret 2020, menteri Pendidikan dan Kebudayaan Republik Indonesia mengeluarkan Surat Edaran Nomor 4 Tahun 2020 Tentang Pelaksanaan Kebijakan Pendidikan Dalam Masa Darurat Penyebaran COVID, dalam Surat Edaran tersebut dijelaskan bahwa proses belajar dilaksanakan di rumah melalui pembelajaran daring/jarak jauh dilaksanakan 
untuk memberikan pengalaman belajar yang bermakna bagi siswa. Belajar di rumah dapat difokuskan pada pendidikan kecakapan hidup antara lain mengenai pandemi Covid-19 (Dewi, 2020:2) .

Model pembelajaran yang diberikan oleh guru bersifat daring dan harus memakai bahan ajar yang bersifat aktif, inovatif dan kreatif agar anak didik tidak merasa bosan dengan kegiatan pembelajaran yang dilakukan secara online. Penyampaian materi melalui daring harus bersifat interaktif sehingga siswa mampu berinteraksi dengan computer atau android sebagai media belajarnya (Choiroh, 2020:1). Mengingat bahwa proses pembelajaran daring bukanlah hal mudah, karena banyaknya kendala, salah satu masalah yang sangat mendasari adalah kendala akses teknologi/jaringan dan kesiapan biaya dari orang tua. Sebagaimana menurut pendapat Nakayama (2007), dari semua literature dalam e-learning mengidentifikasikan bahwa tidak semua siswa akan sukses dalam pembelajaran online. Ini dikarenakan faktor lingkungan belajar dan karakteristik peserta didik.

Terdapat beberapa tantangan belajar secara online diantaranya praktisi pendidikan wajib cakap dalam menyajikan model pembelajaran yang aktif, keadaan ekonomi orang tua yang tidak semua sanggup sediakan minimal mobile android untuk kebutuhan online anaknya, dan tidak semua daerah memiliki jaringan internet yang layak. Supaya pembelajaran tetap aktif, praktisi pendidikan dituntut untuk menggunakan bahan ajar atau media pembelajaran yang aktif dan inovatif. Menurut Keengwe \& Geogina (2012), perkembangan teknologi memberikan perubahan terhadap pelaksanaan pengajaran dan pembelajaran. Kemudahan akses teknologi memberikan dampak yang besar terhadap kualitas pendidikan.

Menanggapi permasahan ini, maka dosen-dosen dan beberapa mahasiswa Program Studi Pendidikan Fisika Universitas Almuslim mengadakan kegiatan pengabdian kepada masyarakat berupa kegiatan webinar nasional dengan tema "Kiat Mengembangkan Strategi Pembelajaran di Era New Normal". Dalam kegiatan webinar ini dibahas tentang optimalisasi ICT dalam meningkatkan peran praktisi pendidikan pada model pembelajaran online, merancang media pembelajaran berbasis video scribe sparkol, teknik instrument evaluasi pembelajaran berbasis kahoot dan teknik quiz online menggunakan aplikasi quizizz.

Video scribe sparkol merupakan software yang bisa digunakan dalam membuat design animasi berlatar putih. Software ini dikembangkan pada tahun 2012 oleh Sparkol (salah satu perusahaan yang ada di Inggris). Menurut Sparkol, Video Scribe adalah cara unik untuk membuat animasi video yang menarik dengan cepat dan mudah. Anda diberdayakan untuk membawa dampak pesan tanpa pengetahuan, teknik atau desain (Air, Jon., dkk, 2014:3). Menurut Al Munawarah (2019: 5), Video Scribe Sparkol adalah perangkat lunak yang berlatar putih yang berisikan narasi dan biasanya digunakan untuk mendesain sebuah program animasi yang dapat dikembangkan menjadi media pembelajaran.

Menurut Suripto, dkk (Nugroho, 2019:2-3), guru dan siswa juga mendapat keuntungan dalam penggunaan teknologi pembelajaran, misalnya teknologi gamifikasi, dimana guru bisa lebih proaktif dan siswa juga bisa mendapatkan sumber materi pelajaran yang tidak terbatas. Melalui aplikasi Kahoot dan quizizz. Kahoot adalah aplikasi gamifikasi pendidikan berbasis daring gratis yang dapat menciptakan suasana pembelajaran lebih menyenangkan. Begitu juga dengan quizizz yang juga merupakan aplikasi berbasis daring gratis yang dapat dibuka melalui browser web.

Melalui aplikasi kahoot dan quizizz ini, guru dapat membuat pembelajaran menjadi sekreatif mungkin, sehingga siswa juga dapat termotivasi dalam belajar. Karena disini, guru merupakan fasilitator yang dapat mendesain pertnayaan, ulangan/kuis, review dan evaluasi pembelajaran. Melalui aplikasi ini memungkinkan siswa untuk bersaing dan memotivasi dalam belajar serta dapat membantu merangsang minat dan meningkatkan konsentrasi siswa (Purba, 2019:5).

\section{METODE}

Metode pelaksanaan yang digunakan pada Pengabdian kepada Masyarakat (PkM) dalam bentuk webinar nasional dengan tema "Pelatihan Inovasi Pembelajaran Mengahadapi Masa Pandemic Covid-19" ini terdiri dari beberapa tahapan mulai dari identifikasi dan analisis masalah yang dialami oleh praktisi pendidikan di seluruh Indonesia, pendaftaran kegiatan webinar, 
menyelenggarakan kegiatan webinar, serta menyusun laporan. Berikut ini akan dideskrisikan rangkaian kegiatan Pengabdian kepada Masyarakat (PKM) dalam bentuk webinar nasional.

1. Identifikasi dan analisis masalah yang dialami oleh praktisi pendidikan di seluruh Indonesia

Tim pengabdian kepada masyarakat program studi pendidikan fisika melakukan analisis permasalahan yang umumnya dialami oleh masyarakat (dalam hal ini praktisi pendidikan) termasuk dosen guru, mahasiswa dan praktisi lainnya pada saat berlangsungnya pandemic covid-19. Permasalahan yang diidentifikasi dan dianalisis terkait dengan permasalahan yang berhubungan dengan pelaksanaan pembelajaran secara daring atau online terutama yang berhubungan dengan strategi pembelajaran secara daring atau online.

2. Membuka pendaftaran acara webinar nasional

Setiap peserta yang akan menjadi peserta kegiatan webinar nasional pengabdian kepada masyarakat harus mendaftarkan diri terlebih dahulu di link pendaftaran http://bit.ly/WebinarPendFisika.

3. Menyelenggarakan kegiatan webinar nasional

Kegiatan webinar nasional ini dilaksanakan setiap hari rabu dan kamis selama 4 hari pada tanggal 8, 9, 15 dan 16 Juli 2020 melalui aplikasi google meet. Kegiatan webinar nasional ini diikuti sebanyak 148 orang yang terdiri dari dosen sebanyak 46 orang, guru sebanyak 44 orang, mahasiswa sebanyak 44 orang dan praktis pendidikan lainnya 14 orang. Kegiatan pengabdian berlangsung dari jam 10.00 WIB sampai dengan jam 12.00 WIB. Kepada seluruh peserta nantinya akan diberikan beberapa fasilitias seperti e-sertifikat dan materi.

\section{Penyusunan laporan}

Setelah kegiatan berlangsung, tim pengabdian akan mengevaluasi kegiatan webinar serta menyusun laporan pengabdian.

\section{HASIL DAN PEMBAHASAN}

Adapun hasil yang di capai pada pengabdian ini diantaranya :

1. Praktisi pendidikan termsuk dosen, guru, mahasiswa dan praktisi pendidikan lainnya memiliki pemahaman terkait perannya dalam penerapan model pembelajaran online.
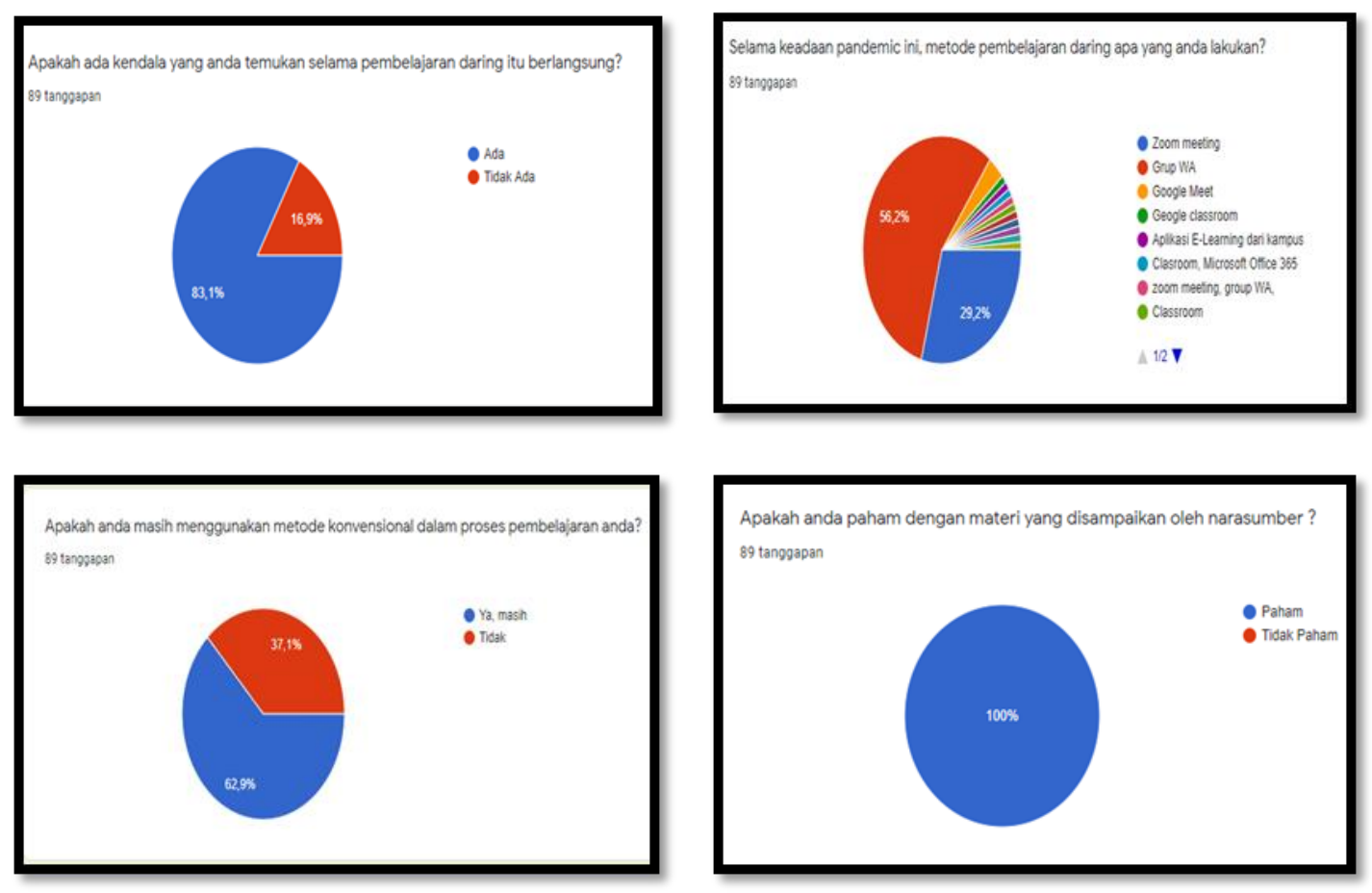

Gambar 1. Hasil survei terhadap metode pembelajaran selama pandemic 
Sebagian besar guru masih menggunakan metode konvensional dalam mengajar sehingga memungkinkan siswa belum mengetahui dan belum mengalami metode-metode pembelajaran terbaru, baik di masa sebelum pandemic maupun pada masa pandemic. Terdapat metode pembelajaran yang beragam, namun pada masa pandemic, metode pembelajaran daring yang banyak dilakukan yaitu melalui WA. Ini dikarenakan banyaknya guru/pengajar lainnya yang masih minim pengetahuan tentang metode/strategi pembelajaran daring. Sehinga memungkinkan banyaknya kendala yang dihadapi. Dengan adanya webinar ini, maka peserta dapat mengimplementasikan dan memahami materi yang telah disampaikan oleh pemateri.

2. Praktisi pendidikan termsuk dosen, guru, mahasiswa dan praktisi pendidikan lainnya memiliki pemahaman dalam merancang media pembelajaran berbasis Sparkol Video Scribe
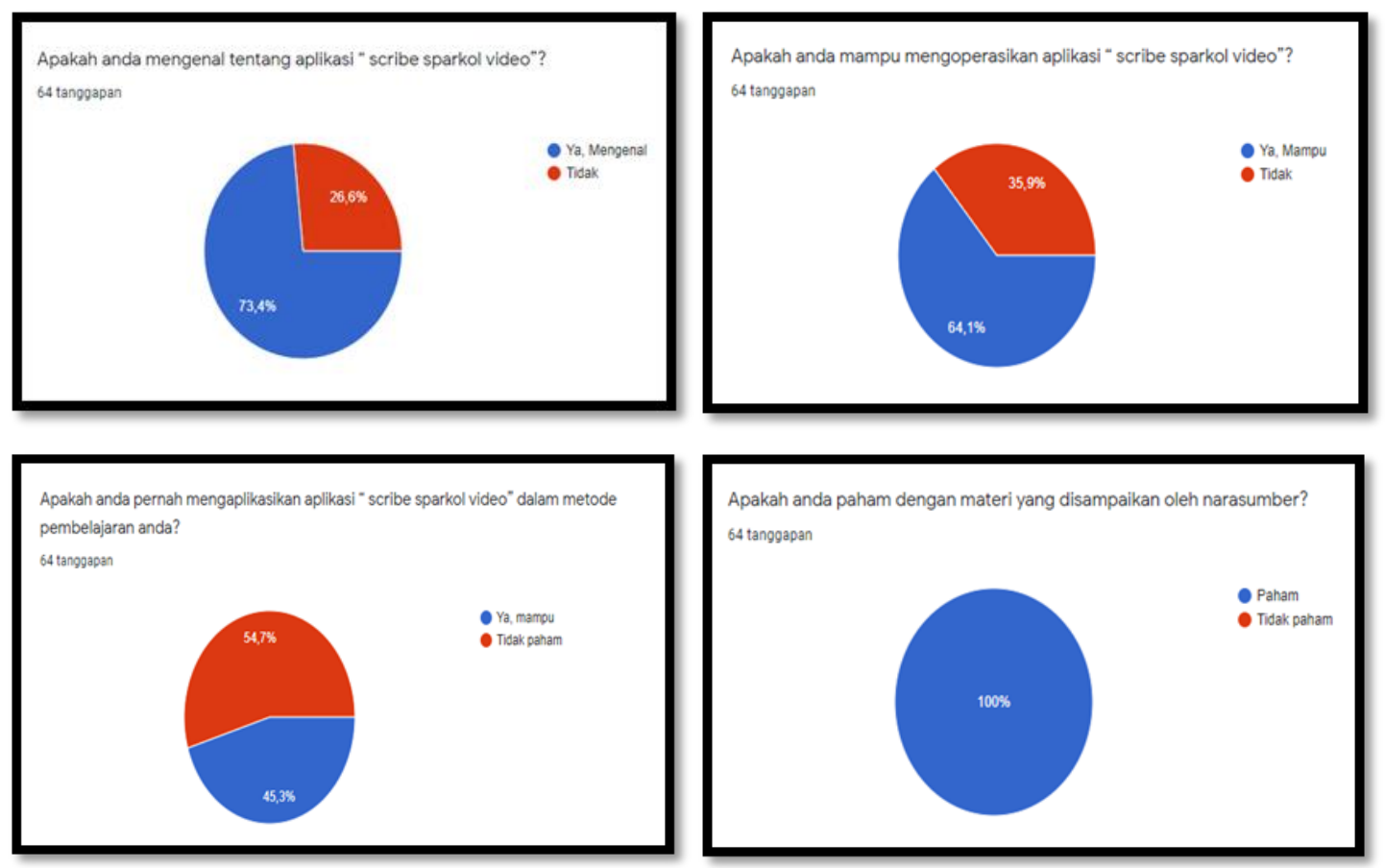

Gambar 2. Hasil survei terhadap penggunaan aplikasi scribe sparkol video

Sebagian besar guru sudah mengenal tentang aplikasi scribe sparkol video. Tetapi belum mengetahui apa dan bagaimana itu aplikasi scribe sparkol video tersebut. Sebagian besar peserta juga mampu mengoperasikan aplikasi tersebut, tetapi belum pernah mengaplikannya dalam metode pembelajaran. Maka melalui pelatihan ini, peserta memahami tentang penggunaan aplikasi scribe sparkol video. Peserta/guru diharapkan memiliki pemahaman dalam merancang media pembelajaran berbasis Sparkol Video Scribe

3. Praktisi pendidikan termsuk dosen, guru, mahasiswa dan praktisi pendidikan lainnya memiliki pemahaman dalam merancang instrument evaluasi pembelajaran berbasis Kahoot.
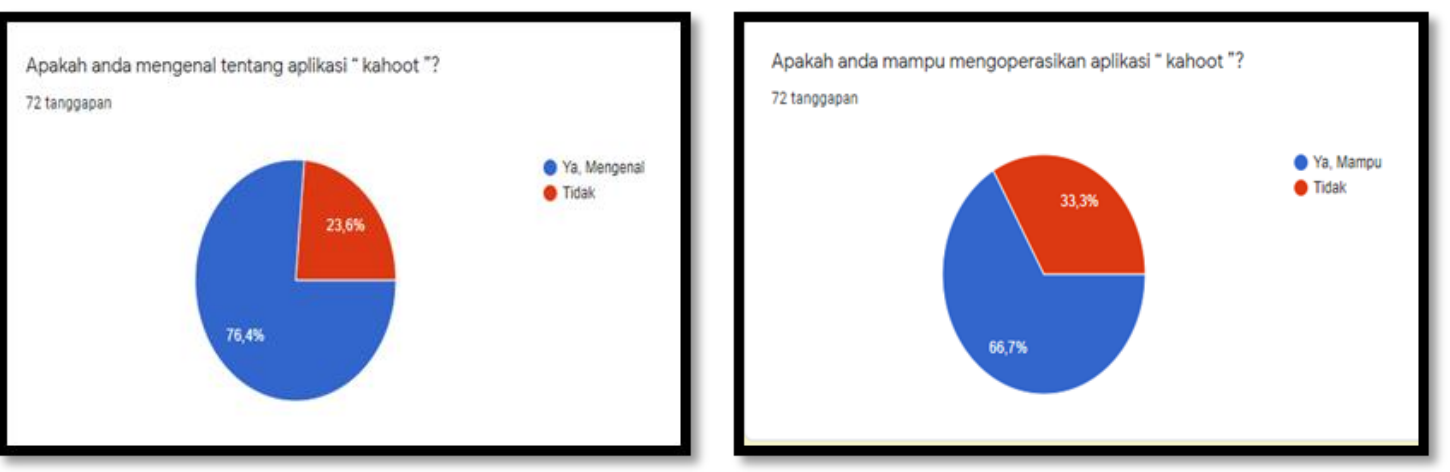


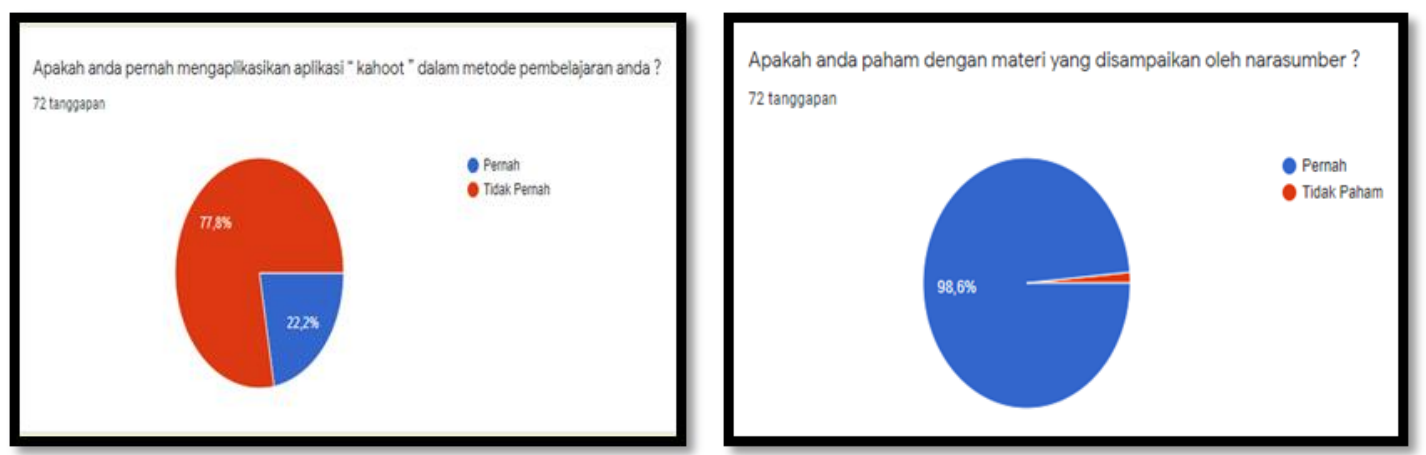

Gambar 3. Hasil survei terhadap penggunaan aplikasi Kahoot

Mengenai aplikasi Kahoot, sebagian peserta sudah mengenal aplikasi ini. Dan peserta mampu mengoperasikan aplikasi tersebut, meskipun sebagian besar peserta tidak pernah mengoperasikan aplikasi tersebut sama sekali, dikarenakan sebagian peserta masih menggunakan metode konvensional. Kemudian melalui penyampaian pemateri tentang aplikasi kahoot, sebagian besar peserta sudah memahami penyampaian materi kahoot tersebut. Dengan adanya pelatihan ini maka peserta guru memiliki pemahaman dalam merancang instrument evaluasi pembelajaran berbasis Kahoot

4. Praktisi pendidikan termsuk dosen, guru, mahasiswa dan praktisi pendidikan lainnya memiliki pemahaman dalam merancang quiz online menggunakan aplikasi Quizizz.

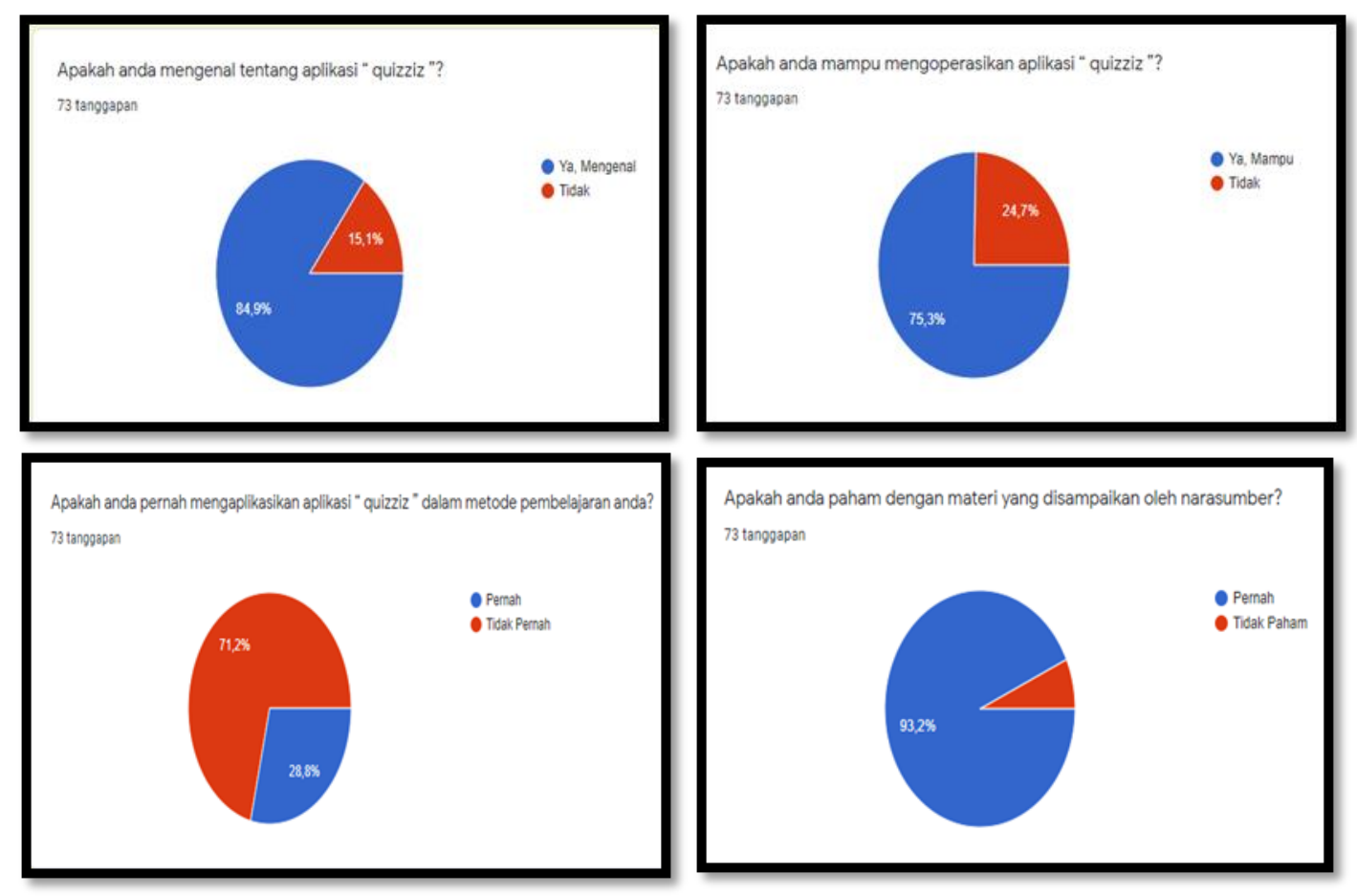

Gambar 4. Hasil survei terhadap penggunaan aplikasi quizizz

Dalam penggunaan aplikasi quizizz ini, sebagian peserta juga sudah mengenal dan mungkin sebagian besar peserta sudah pernah mendengar, dan juga peserta sudah mampu mengoperasikan aplikasi tersebut. Meskipun sudah mampu mengoperasikan aplikasi quizizz tersebut, sebagian banyak peserta belum menerapkan metode tersebut di dalam pembelajaran sehari-hari. Ini dikarenakan, peserta/guru lebih banyak menggunakan metode konvensional, bahkan dalam kondisi pandemic covid-19 sekalipun. Dengan adanya pelatihan ini, maka peserta/guru sudah memiliki pemahaman dan mampu merancang media pembelajaran, misalnya seperti aplikasi quizizz ini. 


\section{SIMPULAN}

Program ini sangatlah penting mengingat proses belajar sudah tidak bisa dilakukan secara tatap muka lagi selama masa pandemic covid-19 ini berlangsung. Praktisi pendidikan termasuk dosen, guru, mahasiswa dan praktisi pendidikan lainnya harus benar-benar berupaya semaksimal mungkin agar tujuan pembelajaran yang disampaikan secara online terselesaikan. Program pelatihan melalui webinar ini diharapkan dapat meningkatkan wawasan praktisi pendidikan termsuk dosen, guru, mahasiswa dan praktisi pendidikan lainnya serta peserta didik lainnya dalam mengembangkan strategi pembelajaran di masa pandemic ini. Meskipun terdapat banyak kendala dalam pelaksanaannya, terutama terkendala jaringan. Maka pelaksanaan program ini merupakan hal yang sangat memotivasi guru dan siswa dalam pelaksanaan pembelajaran. Karena pembelajaran akan terkesan lebih menarik dan menyenangkan.

\section{SARAN}

Semoga tim pengabdian dapat terus memotivasi dan memberikan inovasi pembelajaran lainnya untuk kedepannya guna mengembangkan kemampuannya dalam bidang pendidikan sehingga bisa bermanfaat bagi dirinya dan orang lain.

\section{UCAPAN TERIMA KASIH}

Tim pengabdian mengucapkan banyak-banyak terima kasih kepada berbagai pihak yang telah menberikan dukungannya sehingga kegiatan pengabdian ini terlaksana dengan baik. Tidak lupa pula tim mengucapkan terima kasih kepada seluruh peserta yang telah hadir pada kegiatan pengabdian kami melalui yang dilakukan secara daring, sehingga kegiatan berjalan dengan baik hingga hari terakhir pelaksanaan.

\section{DAFTAR PUSTAKA}

Al Munawarah, Rofiqah. 2019. Sparkol VideoScibe Sebagai Media Pembelajaran. Vol. VIII, No. 2, Juli-Desember 2019.

Air, Jhon., dkk. 2014. Video Scribing How Whiteboard Animation Will Get You Heart. Bristol, UK: Sparkol Book.

Choiroh, Nisaul. 2020. Fektifitas Pembelajaran Daring/E-Learning dalam Pandangan Siswa. Program Studi Pendidikan Bahasa Inggris IAIN Surakarta. https://iainsurakarta.ac.id/\%EF\%BB\%BFefektifitas-pembelajaran-berbasis-daring-e-learning-dalampandangan-siswa/.

Dewi, Wahyu A.F. 2020. Dampak Covid-19 Terhadap Implementasi Pembelajaran Daring di Sekolah Dasar. Edukatif: Jurnal Ilmu Pendidikan. Volume 2 Nomor 1 April 2020. 55-61. ISSN: 2656-8071.

Keengwe, J., \& Georgina. 2012 The digital course training workshop for online learning and teaching. Education and Information Technologies. 17(4), 365-379. https://doi.org/10.1007/s10639-011-9164-x.

Nakayama M, Yamamoto H, \& S. R. (2007). The Impact of Learner Characterics on Learning Performance in Hybrid Courses among Japanese Students. Elektronic Journal E- Learning, Vol.5(3).1.

Nugroho, Dwi Y., Dkk. 2019. Pemanfaatan Teknologi dalam Pendidikan: Penggunaan Fitur Gamifikasi Daring di YPK Penabur Bandarlampung. Prosiding PKM-CSR. Vol.2 (2019). E-ISSN:2655-3570.

Purba, Leony S.L. 2019. Peningkatan Konsentrasi Belajar Mahasiswa Melalui Pemanfaatan Evaluasi Pembelajaran Quizizz pada Mata Kuliah Kimia Fisika I. JDP. Vol. 12, No. 1, April 2019: 29-39. 